\title{
Regional center for complex colonoscopy: yield of neoplasia in patients with prior incomplete colonoscopy
}

\author{
Benjamin L. Bick, Krishna C. Vemulapalli, Douglas K. Rex
}

\begin{abstract}
Background and Aims

Incomplete colonoscopy increases the risk of incident proximal colon cancer post colonoscopy. Incomplete colonoscopy is often followed by barium enema or CT colonography. We sought to describe the yield of completion colonoscopy in a regional center for complex colonoscopy.
\end{abstract}

\section{Methods}

This is a retrospective cohort study of 520 consecutive patients referred to a single colonoscopist over a 14 year period for completion colonoscopy after a previous incomplete exam.

\section{Results}

Colonoscopy was completed to the cecum in 506 of 520 patients (97.3\%). A total of 913 conventional adenomas were removed in 277 patients (adenoma detection rate 53.3\%). There were 184 adenomas $\geq 1 \mathrm{~cm}$ in size or with advanced pathology. There were 525 serrated class lesions removed in 175 patients, including 54 sessile serrated polyps in 26 patients and 41 hyperplastic polyps greater than $1 \mathrm{~cm}$ in 26 patients. Nine colorectal cancers were found. We estimated that approximately $57 \%$ of the conventional adenomas, $58 \%$ of the sessile serrated polyps, 27\% of the hyperplastic polyps, and all 9 cancers detected by the completion colonoscopy were beyond the extent of the previous examination.

This is the author's manuscript of the article published in final edited form as: 


\section{Conclusions}

The yield of completion colonoscopy in a cohort of patients with previous failed cecal intubation was substantial. Regional centers for complex colonoscopy can provide high rates of cecal intubation in cases of incomplete colonoscopy and high yields of lesions in these cases. The regional center for complex colonoscopy is an important medical service. 


\section{Introduction}

Quality guidelines recommend that colonoscopists achieve cecal intubation in at least 90\% of all colonoscopies and 95\% of screening examinations. ${ }^{1,2}$ Interval proximal colon cancer is more common when the cecum is not intubated. ${ }^{3}$

When colonoscopy is incomplete, barium enema or computerized tomographic (CT) colonography are commonly used to examine the colon proximal to the extent reached by colonoscopy. Capsule colonoscopy has been recently approved by the US Food and Drug Administration for this indication, and initial evidence indicates that capsule colonoscopy performs well for polyp detection in this situation. ${ }^{4}$

However, a repeat colonoscopy done by an expert endoscopist avoids radiation exposure and allows for therapy in a single procedure. Our center has the largest reported experience in performing colonoscopy in patients with previous incomplete examinations by other physicians. $^{5,6}$ We have described techniques used to achieve a 96\% cecal intubation rate in 345 patients referred after failed colonoscopy by other physicians, and emphasized the value of water immersion during insertion, particularly in patients with redundant colons..$^{7-9}$

In this report we assess the value of a regional center for complex colonoscopy specifically with regard to completion of previously failed colonoscopies. The impact and benefit of completing colonoscopy in patients with previous incomplete examinations may seem obvious for many patients, but has not been described in detail. Increasingly, regional centers for performance of challenging colonoscopies are being described. ${ }^{10-14}$ In order to better understand the impact of a 
regional center of expertise in colonoscopy on patients with prior incomplete examinations, we describe the findings of completion colonoscopy in 520 consecutive patients referred after incomplete examinations.

\section{Methods}

This study is a retrospective examination of a prospectively created database of all of the patients referred to DKR for previously incomplete colonoscopy. It was approved by the Institutional Review Board at Indiana University Health Partners on June 12, 2015. From July 2001 to March 2015, all patients referred to a single endoscopist (DKR) after prior unsuccessful attempts at cecal intubation by a gastroenterologist or a surgeon were included. They were identified from a colonoscopy database that contains all patients referred to DKR because of prior incomplete colonoscopy.

The database includes patient demographics, indications, methods of colonoscopy, duration of procedure, extent of prior colonoscopy and reasons for failure of cecal intubation for the prior colonoscopy. Serrated lesions were those read by the pathologist as sessile serrated polyps (sessile serrated adenomas), hyperplastic polyps, or traditional serrated adenomas.

The approach to colonoscopy in patients with prior failed colonoscopies was previously described and briefly summarized here. ${ }^{7,9}$ Generally, standard adult colonoscopes were used for patients with redundant colons, and since 2008 with water immersion. Overtubes were used in cases where the above tools were unsuccessful. In patients with angulated or narrowed sigmoid colons as the cause of failed colonoscopy, pediatric colonoscopes were used in most cases but in 
some cases a push enteroscope (usually the Olympus SIF-180, Olympus Corp, Center Valley, PA) or an upper endoscope was used. Again, water immersion was used routinely since 2008. Guide wire exchange was used in some cases if an upper endoscope was used to pass a difficult angulation but unable to reach the cecum. ${ }^{15}$ Propofol was used for sedation in most cases; with monitored anesthesia care since February 2010.

Statistical analysis was performed using SPSS version 22 (IBM, New York, NY). Means and standard deviations were calculated for continuous variables. Ninety-five percent confidence intervals were calculated using the efficient-score method corrected for continuity.

\section{Results}

There were 520 consecutive patients. Mean age was 64.2 years (SD 11.2 y; range 17-93 y), and 355 (68.3\%) were women. Prior incomplete colonoscopies were performed by gastroenterologists or surgeons. Referrals were made by a gastroenterologist in 370 cases (71.2\%), a surgeon in 61 cases (11.7\%), a primary physician in 68 cases $(13.1 \%)$, and selfreferred in 21 cases $(4.4 \%)$.

Table 1 shows the indications for colonoscopy other than “prior incomplete colonoscopy”. Reasons for failure of prior colonoscopy are shown in Table 2.

Colonoscopy was complete to the cecum (full exposure of the medial wall between the ileocecal valve and the appendiceal orifice) in 506 of 520 patients (97.3\%). The mean time to cecal 
intubation was 13.6 minutes (SD $9.3 \mathrm{~min}$; range 1-57.7 min). The equipment relied on for cecal intubation and the maneuvers used are shown in Table 3. Water immersion was used in 352 patients (67.7\%). Propofol (with or without other sedatives), administered prior to February 2010 by registered nurses supervised by the endoscopist $(n=127)$ and after February 2010 by Monitored Anesthesia Care $(n=254)$ was used in 381 total cases, with a success rate in cecal intubation of 97.1\% (370/381). Opiods and benzodiazepines were used in the remaining 139 cases, with a cecal intubation rate of $97.8 \%(136 / 139)$.

A total of 913 conventional adenomas were removed in 277 patients, for an adenoma detection rate (ADR) of 53.3\% and 1.76 adenomas per colonoscopy (APC). This includes a total of 184 advanced adenomas ( $>1 \mathrm{~cm}$ in size or advanced pathology) removed in 101 patients, with an advanced adenoma detection rate of $19.4 \%$ and advanced adenomas per colonoscopy of 0.35 . A total of 525 serrated lesions were removed in 175 patients, with 1.01 serrated lesions per colonoscopy (SPC). Of these, 54 lesions in 26 patients were read as sessile serrated polyps by the pathologists, including 10 that were $\geq 1 \mathrm{~cm}$ in size. In addition, there were 41 hyperplastic polyps $\geq 1 \mathrm{~cm}$ in size in 26 patients. Table 4 summarizes lesions found during colonoscopy by location. There were nine colorectal cancers found (3 with and 6 without lymph node metastases) including 2 in the cecum, 3 in the ascending, 1 in the transverse, 1 in the descending, and 2 in the sigmoid colon.

If only the 446 patients with no prior radiographic imaging study were considered, the ADR was 52.9\%, APC 1.75, advanced adenoma detection rate 19.7\%, and advanced adenomas per 
colonoscopy 0.29. Table 5 shows that the yield of lesions was substantial for all colonoscopy indications.

Based on reported extent of the previous examinations, we estimated that approximately $57 \%$ of the adenomas, $58 \%$ of the sessile serrated polyps, $27 \%$ of the hyperplastic polyps, and all 9 cancers detected by the completion colonoscopy were beyond the extent of the previous examination (as opposed to reached but missed during the incomplete examination).

Of the 14 patients with incomplete examinations by DKR, there were 8 patients with diseased colon segments that could not be passed or which provided "fixed resistance" to scope passage after being passed. The anatomic diagnoses in these 8 patients were ischemic colitis with stricture $(n=1)$, sigmoid fixation after pelvic surgery $(n=1)$, obstructing colon cancer $(n=1)$, NSAID induced stricture $(n=1)$, radiation stricture $(n=1)$, diverticulitis related stricture $(n=2)$, and intra-abdominal metastases from breast cancer $(\mathrm{n}=1)$. Two patients had abdominal wall hernias that could not be reduced prior to starting the procedure. In both cases the colonoscope tip could pass the distal point of the herniated transverse colon but could not pass the proximal point of the herniation despite manual attempts to advance the colonoscope through the herniated bowel. Four patients had intractable looping as the cause of failure. Two of these four patients had a second attempt by DKR at cecal intubation at later dates, and both repeat attempts by DKR were successful. These two patients were the only patients of the 14 failed procedures in whom DKR attempted cecal intubation two or more times on different days.

\section{Discussion}


In this report we describe the largest experience of patients referred for completion colonoscopy after a prior incomplete examination. We previously described methods used to complete a colonoscopy after prior attempts at intubating the cecum had failed. ${ }^{7,9}$ In a population of 520 consecutive referred patients, we again found that in patients with a prior incomplete colonoscopy, cecal intubation can be achieved with routine equipment and maneuvers in the overwhelming majority (97\%). In this report we describe the yield of neoplasia during completion colonoscopies at a referral center. These data are relevant to whether establishment of regional referral centers for complex colonoscopies is warranted.

The yield of completion colonoscopy in this cohort was substantial, with 53\% having at least one conventional adenoma, 19\% having an advanced conventional adenoma, $5 \%$ having a sessile serrated polyp, $5 \%$ having a hyperplastic polyp $\geq 1 \mathrm{~cm}$, and $1.7 \%$ having cancer. We estimated that more than half of the neoplasia detected at completion colonoscopy was proximal to the extent of the previous incomplete examination as opposed to reached but missed during the prior examination. In this study $78 \%$ of advanced conventional adenomas and $77 \%$ of the sessile serrated polyps were estimated to be proximal to the splenic flexure (Table 4), supporting the suggestion that a very high yield for completion colonoscopy results mostly from achieving access to the proximal colon. After removing patients referred for abnormal imaging tests, the yield of neoplasia from completion colonoscopy was still very substantial. Thus, these data support the value of establishing regional expertise in complex colonoscopy, and that referral directly to the regional center without intervening radiographic imaging is reasonable and appropriate. 
Some previous studies have described techniques and yields of repeat colonoscopy in patients with prior incomplete colonoscopies ${ }^{6,16-31}$. Our series has several strengths, including its large size (this series accounts for more than half of all reported cases) and referral of all cases from other gastroenterologists and surgeons. We also excluded patients with prior incomplete examinations because of inadequate preparation, a policy followed in most but not all series (Table 6). Thus, nearly all patients in our series had a structural cause (a redundant colon with looping or an angulated sigmoid colon) underlying the prior incomplete colonoscopy. Despite that, colonoscopy was completed in the overwhelming percentage of cases (97\%) entirely with widely available endoscopes not including double or single balloon enteroscopes. Although double and single balloon enteroscopes have become the mainstay of completion colonoscopy in some centers (Table 6), our series demonstrates that high rates of completion are achievable without these specialized endoscopes, which are still not widely available. The addition of water immersion to standard colonoscopy techniques has greatly simplified the procedure when the cause of the prior failure is a redundant colon ${ }^{9}$. The use of standard colonoscopes may provide an advantage over single and double balloon enteroscopes when complex polypectomies must be completed after cecal intubation. We're uncertain whether the 14 cases in this series in which colonoscopy was not completed might have been successfully intubated to the cecum using balloon enteroscopes. The best approach for the regional center for complex colonoscopy may be to have one or more colonoscopy experts skilled in the use of both conventional and balloon instruments.

Limitations of this study include the selection bias associated with the referral system. However, some degree of referral bias would be expected in any regional center for complex colonoscopy. 
Further, the yield remained high after exclusion of patients with positive radiographic imaging studies, the most obvious source of referral bias. Second, the location of polyps and whether they were proximal to the extent of the prior colonoscopy can only be estimated for many lesions. Therefore, our estimates of the fraction of lesions not reached vs. reached but not detected are just that, i.e. estimates only. The proximal colon location of most of the advanced lesions suggests that many were proximal to the extent of the previous examination. Next, review of the serrated lesions by an expert pathologist might increase the number of sessile serrated polyps identified, but would not change the overall conclusions. Finally, all of the colonoscopies in this study were performed by a single expert, but this scenario may be expected in some regional centers for complex colonoscopy ${ }^{16}$.

In summary, regional centers for complex colonoscopy can provide high rates of cecal intubation in cases of incomplete colonoscopy and high yields of neoplasia in these cases. The regional center for complex colonoscopy is an important medical service. 


\section{References}

1. Rex DK, Schoenfeld PS, Cohen J, et al. Quality indicators for colonoscopy. Gastrointest Endosc 2015;81:31-53.

2. Rex DK, Bond JH, Winawer S, et al. Quality in the technical performance of colonoscopy and the continuous quality improvement process for colonoscopy: recommendations of the U.S. Multi-Society Task Force on Colorectal Cancer. Am J Gastroenterol 2002;97:1296-308.

3. Baxter NN, Sutradhar R, Forbes SS, Paszat LF, Saskin R, Rabeneck L. Analysis of administrative data finds endoscopist quality measures associated with postcolonoscopy colorectal cancer. Gastroenterology 2011;140:65-72.

4. Spada C, Hassan C, Barbaro B, et al. Colon capsule versus CT colonography in patients with incomplete colonoscopy: a prospective, comparative trial. Gut 2015;64:272-81.

5. Gawron AJ, Veerappan A, Keswani RN. High success rate of repeat colonoscopy with standard endoscopes in patients referred for prior incomplete colonoscopy. BMC Gastroenterol 2014;14:56.

6. Ridolfi TJ, Valente MA, Church JM. Achieving a complete colonic evaluation in patients with incomplete colonoscopy is worth the effort. Dis Colon Rectum 2014;57:383-7.

7. Rex DK, Chen SC, Overhiser AJ. Colonoscopy technique in consecutive patients referred for prior incomplete colonoscopy. Clin Gastroenterol Hepatol 2007;5:879-83.

8. Rex DK, Goodwine BW. Method of colonoscopy in 42 consecutive patients presenting after prior incomplete colonoscopy. Am J Gastroenterol 2002;97:1148-51.

9. Vemulapalli KC, Rex DK. Water immersion simplifies cecal intubation in patients with redundant colons and previous incomplete colonoscopies. Gastrointest Endosc 2012;76:812-7.

10. Liaquat $\mathrm{H}$, Rohn E, Rex DK. Prophylactic clip closure reduced the risk of delayed postpolypectomy hemorrhage: experience in 277 clipped large sessile or flat colorectal lesions and 247 control lesions. Gastrointest Endosc 2013;77:401-7.

11. Moss A, Williams SJ, Hourigan LF, et al. Long-term adenoma recurrence following wide-field endoscopic mucosal resection (WF-EMR) for advanced colonic mucosal neoplasia is infrequent: results and risk factors in 1000 cases from the Australian Colonic EMR (ACE) study. Gut 2015;64:57-65.

12. Binmoeller KF, Weilert F, Shah J, Bhat Y, Kane S. "Underwater" EMR without submucosal injection for large sessile colorectal polyps (with video). Gastrointest Endosc 2012;75:1086-91.

13. Woodward TA, Heckman MG, Cleveland P, De Melo S, Raimondo M, Wallace M. Predictors of complete endoscopic mucosal resection of flat and depressed gastrointestinal neoplasia of the colon. Am J Gastroenterol 2012;107:650-4.

14. Waye JD. Difficult colonoscopy. Gastroenterol Hepatol (N Y) 2013;9:676-8.

15. Ness RM, Gottlieb K, Rex DK, Lehman GA. Difficult sigmoid colon intubation: guide wire exchange technique. Gastrointest Endosc 1996;44:99-101.

16. Brahmania M, Park J, Svarta S, Tong J, Kwok R, Enns R. Incomplete colonoscopy: maximizing completion rates of gastroenterologists. Can J Gastroenterol 2012;26:589-92.

17. Becx MC, Al-Toma A. Double-balloon endoscopy: an effective rescue procedure after incomplete conventional colonoscopy. Eur J Gastroenterol Hepatol 2014;26:519-22.

18. Nemoto D, Isohata N, Utano K, Hewett DG, Togashi K. Double-balloon colonoscopy carried out by a trainee after incomplete conventional colonoscopy. Dig Endosc 2014;26:392-5.

19. Keswani RN. Mo1221 Successful Colonoscopy in Patients Referred for Prior Incomplete Colonoscopy Does Not Require More Time but Often Requires Use of a Different Endoscope. Gastrointestinal Endoscopy 2012;75:AB355.

20. Hotta K, Katsuki S, Ohata K, et al. A multicenter, prospective trial of total colonoscopy using a short double-balloon endoscope in patients with previous incomplete colonoscopy. Gastrointest Endosc 2012;75:813-8. 
21. Keswani RN. Single-balloon colonoscopy versus repeat standard colonoscopy for previous incomplete colonoscopy: a randomized, controlled trial. Gastrointest Endosc 2011;73:507-12.

22. Matsushita M, Shimatani M, Tanaka T, Fukata N, Kawamata S, Okazaki K. Short double-balloon enteroscope for previously failed colonoscopy. Gastrointest Endosc 2011;73:854-5; author reply 5.

23. Schembre DB, Ross AS, Gluck MN, Brandabur JJ, McCormick SE, Lin OS. Spiral overtube-assisted colonoscopy after incomplete colonoscopy in the redundant colon. Gastrointest Endosc 2011;73:515-9.

24. Coppola F, Gaia S, Cosimato M, Recchia S. Enteroscope without overtube for cecal intubation after an incomplete colonoscopy. Dig Liver Dis 2011;43:475-7.

25. Teshima CW, Aktas H, Haringsma J, Kuipers EJ, Mensink PB. Single-balloon-assisted colonoscopy in patients with previously failed colonoscopy. Gastrointest Endosc 2010;71:1319-23.

26. Moreels TG, Macken EJ, Roth B, Van Outryve MJ, Pelckmans PA. Cecal intubation rate with the double-balloon endoscope after incomplete conventional colonoscopy: a study in 45 patients. J Gastroenterol Hepatol 2010;25:80-3.

27. Shida T, Takano S, Kaiho M, Miyazaki M. Transparent hood attached to a gastroscope: a simple rescue technique for patients with difficult or incomplete colonoscopy. Endoscopy 2008;40 Suppl 2:E139.

28. Monkemuller K, Knippig C, Rickes S, Fry LC, Schulze A, Malfertheiner P. Usefulness of the doubleballoon enteroscope in colonoscopies performed in patients with previously failed colonoscopy. Scand J Gastroenterol 2007;42:277-8.

29. Pasha SF, Harrison ME, Das A, Corrado CM, Arnell KN, Leighton JA. Utility of double-balloon colonoscopy for completion of colon examination after incomplete colonoscopy with conventional colonoscope. Gastrointest Endosc 2007;65:848-53.

30. Gay G, Delvaux M. Double-balloon colonoscopy after failed conventional colonoscopy: a pilot series with a new instrument. Endoscopy 2007;39:788-92.

31. Kaltenbach T, Soetikno R, Friedland S. Use of a double balloon enteroscope facilitates caecal intubation after incomplete colonoscopy with a standard colonoscope. Dig Liver Dis 2006;38:921-5. 
Table 1. Indications for colonoscopy in 520 consecutive patients referred for incomplete colonoscopy

\begin{tabular}{|l|l|}
\hline Indication & Frequency (\%) \\
\hline Screening or surveillance of polyps & $296(56.9 \%)$ \\
\hline Abnormal CT colonography or barium enema & $74(14.2 \%)$ \\
\hline Therapy of visualized polyp & $21(4.0 \%)$ \\
\hline Surveillance for history of colorectal cancer & $13(2.5 \%)$ \\
\hline Anemia or gastrointestinal bleeding & $99(19.0 \%)$ \\
\hline Inflammatory bowel disease & $17(3.3 \%)$ \\
\hline
\end{tabular}


Table 2. Reasons for failure to complete prior colonoscopy in 520 patients.

\begin{tabular}{|l|l|}
\hline Reason for failure & Frequency \\
\hline Looping/redundant colon & $280(53.8 \%)$ \\
\hline Sigmoid fixation/angulation & $202(38.8 \%)$ \\
\hline Both sigmoid angulation \& looping colon & $30(5.8 \%)$ \\
\hline Issues with sedation & $8(1.5 \%)$ \\
\hline
\end{tabular}


Table 3. Equipment and maneuvers critical to cecal intubation in 505 patients

\begin{tabular}{|l|l|l|}
\hline Equipment used & & \\
\hline & Adult colonoscope & $278(55.0 \%)$ \\
\hline & Pediatric colonoscope & $119(23.6 \%)$ \\
\hline & Upper endoscope & $35(6.9 \%)$ \\
\hline & Enteroscope & $24(4.7 \%)$ \\
\hline & Overtube with any scope & $30(5.9 \%)$ \\
\hline & Guidewire exchange & $19(3.8 \%)$ \\
\hline
\end{tabular}


Table 4. Location of resected polyps and cancers

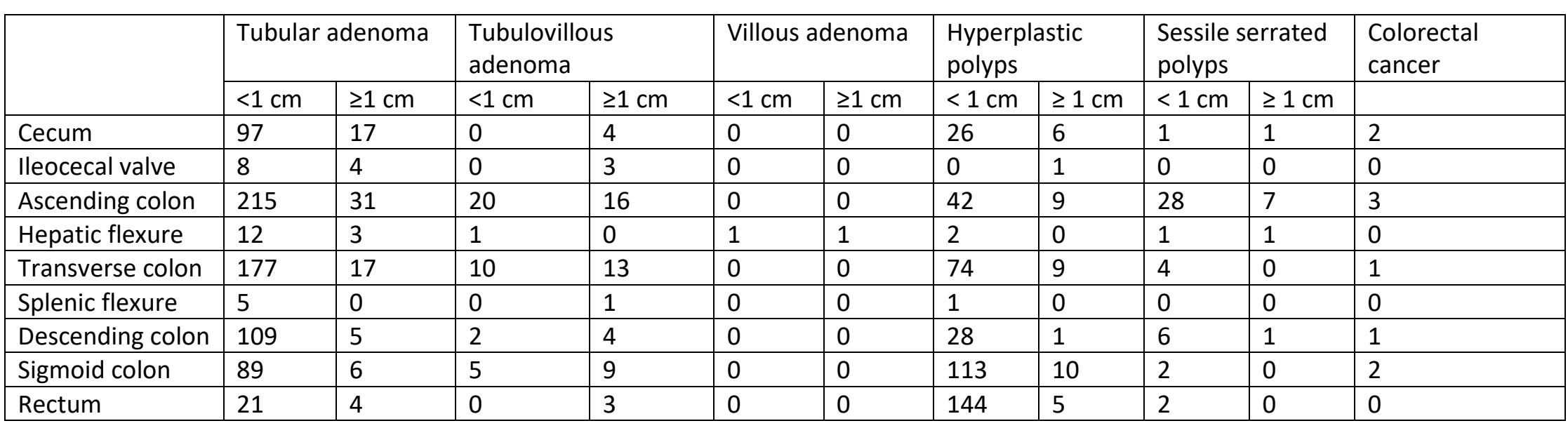


Table 5. Yield of repeat colonoscopy at our center by indication

\begin{tabular}{|c|c|c|c|c|c|c|c|}
\hline Indication & $\begin{array}{l}\text { Non- } \\
\text { advanced } \\
\text { adenomas }\end{array}$ & $\begin{array}{l}\text { Adenoma } \\
\text { detection rate } \\
(\%)\end{array}$ & $\begin{array}{l}\text { Advanced } \\
\text { adenomas }\end{array}$ & $\begin{array}{l}\text { Advanced } \\
\text { adenoma } \\
\text { detection rate } \\
(\%)\end{array}$ & $\begin{array}{l}\text { Sessile } \\
\text { serrated } \\
\text { polyps }\end{array}$ & $\begin{array}{l}\text { Hyperplastic } \\
\text { polyps } \geq 10 \\
\mathrm{~mm}\end{array}$ & Cancer \\
\hline $\begin{array}{l}\text { Screening or } \\
\text { surveillance } n=296\end{array}$ & 476 & 59.5 & 131 & 21.3 & 21 & 24 & 4 \\
\hline $\begin{array}{l}\text { Abnormal imaging } \\
n=74\end{array}$ & 100 & 54.1 & 21 & 17.6 & 16 & 6 & 1 \\
\hline $\begin{array}{l}\text { Polyp visualized but } \\
\text { not reached } n=21\end{array}$ & 69 & 85.7 & 20 & 57.1 & 8 & 9 & 1 \\
\hline $\begin{array}{l}\text { History of colorectal } \\
\text { cancer } n=13\end{array}$ & 13 & 53.8 & 4 & 23.1 & 0 & 0 & 1 \\
\hline $\begin{array}{l}\text { Bleeding (anemia, } \\
\text { occult blood) n=99 }\end{array}$ & 64 & 30.3 & 7 & 9.1 & 7 & 1 & 2 \\
\hline $\begin{array}{l}\text { Inflammatory Bowel } \\
\text { Disease } n=17\end{array}$ & 7 & 35.3 & 1 & 5.9 & 2 & 1 & 0 \\
\hline
\end{tabular}


Table 6. Patients, instruments and success rate of repeat colonoscopy in patients with prior incomplete colonoscopies

\begin{tabular}{|c|c|c|c|c|c|c|c|}
\hline $\begin{array}{l}\text { Author/ } \\
\text { reference }\end{array}$ & Year & $\begin{array}{l}\text { Number of } \\
\text { Patients }\end{array}$ & $\begin{array}{l}\text { Largely } \\
\text { referred from } \\
\text { outside } \\
\text { institutions }\end{array}$ & $\begin{array}{l}\text { Success in } \\
\text { intubation (\%) }\end{array}$ & $\begin{array}{l}\text { Balloon } \\
\text { enteroscope } \\
\text { or other } \\
\text { special scope }\end{array}$ & $\begin{array}{l}\text { \% with poor } \\
\text { preparation as } \\
\text { a cause of } \\
\text { failure }\end{array}$ & ADR (\%) \\
\hline Bick/ current & 2015 & 520 & Yes & 97.3 & No & 0 & 53.3 \\
\hline Ridolfi $^{6}$ & 2014 & 79 & No & NS & No & 34 & 24 \\
\hline Becx $^{17}$ & 2014 & 114 & No & 88.6 & Yes & 0 & 42.1 \\
\hline Nemoto ${ }^{18}$ & 2014 & 28 & No & 100 & Yes & 0 & NS \\
\hline Brahmania $^{16}$ & 2012 & 90 & Yes & 96.6 & No & 11 & NS \\
\hline Keswani 19 & 2012 & 70 & NS & 97.1 & Yes, in $19.1 \%$ & NS & 31.4 \\
\hline Hotta 20 & 2012 & 110 & No & 100 & Yes & 0 & 50 \\
\hline Keswani $^{21}$ & 2011 & 30 & No & $\begin{array}{r}92.9 \\
50\end{array}$ & $\begin{array}{r}\text { Yes } \\
\text { No }\end{array}$ & 0 & 11.8 \\
\hline Matsushita 22 & 2011 & 23 & NS & 95.6 & Yes & NS & NS \\
\hline Schembre ${ }^{23}$ & 2011 & 24 & No & 92 & $\begin{array}{r}\text { Spiral } \\
\text { overtube }\end{array}$ & No & 54.2 \\
\hline Coppola $^{24}$ & 2011 & 79 & No & 93.6 & $\begin{array}{r}\text { Push } \\
\text { enteroscope }\end{array}$ & 0 & 31.6 \\
\hline Teshima ${ }^{25}$ & 2010 & 23 & Yes & 96 & Yes & NS & PDR 26.1 \\
\hline Moreels ${ }^{26}$ & 2009 & 45 & No & 93 & Yes & 0 & PDR 43 \\
\hline Shida $^{27}$ & 2008 & 52 & No & 88.5 & $\begin{array}{r}\text { Gastroscope } \\
\text { with cap }\end{array}$ & 0 & NS \\
\hline Mönkemüller ${ }^{28}$ & 2007 & 7 & NS & 100 & Yes & 0 & 43 \\
\hline Pasha ${ }^{29}$ & 2007 & 16 & No & 85.7 & Yes & 0 & PDR 37.5 \\
\hline Gay $^{30}$ & 2007 & 29 & NS & 96.5 & Yes & NS & PDR 26.1 \\
\hline Kaltenbach ${ }^{31}$ & 2006 & 20 & No & 95 & Yes & 0 & 25 \\
\hline
\end{tabular}

ADR: adenoma detection rate

PDR: polyp detection rate

NS: not stated 